\title{
EDITORIAL
}

\section{Beyond the crunch}

The effects of the credit crunch have been prominent in many industries in the past year, and, of course, the biopharma industry is not immune, especially companies that need funding. Nevertheless, many of the challenges for drug discovery and development in the next year and beyond are more familiar, but hopefully some potential solutions are emerging.

At the end of 2008, a group of high-profile figures associated with the UK biotech industry joined the growing number of leaders from other industries around the world asking for a government bailout - in this case involving the establishment of two UK£500 million funds. Without such funding soon, a host of biotech companies will fail in the next year, say the supporters of the proposal.

Although predicting the effects of the credit crunch on the biopharma industry in the coming year is a risky endeavour, some broad possibilities such as this seem to have become generally recognized. On one hand, smaller, less mature, companies are increasingly having to cut staff and terminate projects to stretch out their rapidly dwindling cash supplies, even in the United States, which has generally had a much more positive environment for biotech funding than the UK and elsewhere. Indeed, it has been reported that more than 100 public US biotech companies have less than 6 months' worth of cash left.

Large biotech and pharma companies, on the other hand, generally have considerable cash reserves, and several have already stated their intentions to harness this position through licensing deals and acquisitions. For example, Novo Nordisk recently announced that they might spend as much as US $\$ 2$ billion on takeovers in the next 12 months. Thus, the general impression is that for larger companies the credit crunch could provide opportunities to replenish pipelines through deals on terms that are considerably more favourable for them than would have been likely a year or so ago.

However, regardless of whether the credit crunch represents a serious threat or a potential opportunity for a particular company, a crucial challenge for the biopharma industry in general is still lacklustre late-stage pipelines. This challenge is made particularly acute by the widely acknowledged 'patent cliff', which is now close to reaching its steepest point. According to Datamonitor, between 2007 and 2012, the top 50 pharma companies face patent expiries on $\$ 115$ billion worth of drugs ${ }^{1}$. The losses in sales are anticipated to be particularly severe from 2011/2012 onwards: products that lose patent protection in the key US market in these 2 years alone include the multibillion-dollar blockbusters Lipitor (Pfizer),
Advair (GlaxoSmithKline), Plavix (Sanofi-Aventis/ Bristol-Myers Squibb) and Seroquel (AstraZeneca).

Moreover, it is well acknowledged that many of the larger companies are not favourably positioned to offset this vast loss of revenue through the introduction of new drugs. For example, an analysis of the predicted performance of the 14 largest biopharma companies forecasted that, by 2012 , the group overall would generate only $\$ 0.26$ in new product revenue for every dollar of revenue lost owing to issues such as patent expiries ${ }^{2}$. Indeed, of the 14 companies, only two had a forecasted replacement ratio - the ratio of new-product revenue to establishedproduct revenue lost - greater than 1.0 in 2012.

Unsurprisingly, despite the ongoing cost-cutting programmes - which have recently seen more than 50,000 jobs cut or planned to be cut from large biopharma companies - some industry analysts are speculating that the dual pressures of imminent patent expiries and lack of new drugs will be the catalyst for another wave of largecompany mergers and acquisitions. However, given that past experience with mega-mergers suggests that productivity often suffers considerably for a long period postmerger, such short-term strategies could further damage the industry's long-term chances of regaining its vitality.

Nevertheless, as highlighted in our traditional yearly news round-up on page 5 , some promising novel alternatives for improving overall R\&D productivity are emerging, perhaps most notable of which are a new breed of partnerships. For example, this year has seen the establishment of a range of closer and more collaborative relationships between large pharma companies and academic institutions, which might help to more effectively and rapidly link basic research advances in academia to the translational expertise of pharma. Furthermore, collaborations between companies in areas that might have previously been considered competitive, such as identifying biomarkers of toxicity, have reported their first successes. It must be hoped that some of these innovative partnerships will help provide a solution to the fundamental problems that had been plaguing the biopharma industry for years before the credit crunch took hold.

1. The Pharmaceutical Industry 2008 (Datamonitor, March 2008) 2. Goodman, M. Nature Rev. Drug Discov. 7, 795 (2008). 